\title{
Tricuspid Valve Endocarditis, a Single Center Experience to Reduce the Chance of Atrioventricular Block
}

\author{
Mehrdad Salehi ${ }^{1}$, Ali Reza Bakhshandeh ${ }^{1 *}$, Mehrzad Rahmanian ${ }^{1}$, Neal Kraus ${ }^{3}$, Jamshid \\ Mirzaei $^{4}$, Kianoush Saberi ${ }^{2}$, Mahmood Alemohammad ${ }^{2}$, Keivan Sobhanian ${ }^{1}$ and Maziar \\ Karamnejad \\ ${ }^{1}$ Department of cardiovascular surgery, Imam Khomeini hospital complex, Tehran University of medical sciences, Tehran, \\ Iran \\ ${ }^{2}$ Department of anesthesia, Imam Khomeini hospital complex, Tehran University of medical sciences, Tehran, Iran \\ ${ }^{3}$ Board Certified American Board of Internal Medicine. Attending physician at Rocky Mountain Senior Care Golden, \\ Colorado, USA \\ ${ }^{4}$ Board Certified American Board of Internal Medicine. Attending physician at Swedish Medical center, Denver, Colorado,
} USA

Received: 01 April, 2017 ; Accepted: 01 June, 2017; Published: 12 June, 2017

*Corresponding author: Ali Reza Bakhshandeh, MD, Associate professor in cardiac surgery, Department of cardiovascular surgery, Imam Khomeini Hospital Complex, Tehran, Iran, Cell phone : +98 9122204622,Fax no: +98 21 66581595; E-mail: abakhshandeh@ymail.com

\section{Abstract}

Background: Tricuspid Valve Endocarditis (TVE) in Intravenous Drug Abusers (IVDAs) is one of the leading causes of disability as it entails both cardiovascular and neurological complications which eventually usher in socioeconomic problems. The most practical approach is debated given variables such how to manage patients with elevated pulmonary artery pressures, what type of prosthetic valve to employ, how to mitigate the risk of post-operative reinfection, and strategies to reduce the possibility of development of Atrioventricular (AV) block. In this study, we present a novel technique for valve replacement to reduce or altogether eliminate the chance of developing AV block.

Methods: Between December 2003 to November 2013, 243 consecutive patients with tricuspid valve endocarditis were enrolled in this study. This study was conducted in Imam Khomeini Hospital Complex, Tehran University of Medical Sciences. After January 2007 and whenever the septal leaflet was destroyed, and repair was not feasible, we sewed a double layer strip of pericardium along the septal leaflet annulus to make an anchoring cuff for Tricuspid Valve Replacement (TVR) stitches. The primary end point of this study was to compare the frequency of $\mathrm{AV}$ block following valve replacement before and after application of our novel technique.

Results: All-cause mortality was in 27 (11.1\%) patients. AV block was seen in 11 (22.9\%) patients who underwent TVR. Mean survival in TVR patients with sinus rhythm after operation was $39.2 \pm 4$ months and in patients with AV block was $2.9 \pm 1.2$ months, (p-value: .000). In logistic regression analysis, developing AV block on the technique of TVR was statistically significant.

Conclusion: In our findings, whenever resection of destroyed septal leaflet is inevitable, utilizing our novel technique of TVR is a practical strategy to reduce or altogether abolish the chance of developing AV block.

Keywords: Tricuspid valve; Endocarditis; Drug abuser; Outcome study; Atrioventricular block

\section{Introduction}

Tricuspid valve endocarditis (TVE) occurs predominantly in (IVDAs) and occasionally in those with a central venous line, pacemakers or AICD, and those on hemodialysis [1]. Nearly $60 \%$ of these patients are frequently admitted to the hospital as a result of acute infection, and IE is implicated in 5 to $15 \%$ of these cases [2,3]. There are several articles in the literature discussing the epidemiologic, clinical, and prognostic features of this issue.

The most practical approach is still being debated such as the best approach in patients with high pulmonary artery pressure, type of prosthetic valve, reinfection, and strategies to reduce the risk of $\mathrm{AV}$ block. $\mathrm{AV}$ block after tricuspid valve replacement is an untoward complication which is more frequent whenever septal leaflet is destroyed and thus should be excised. Need for permanent pacemaker and its risk of reinfection and prolonged hospital stay in these patients is a disastrous complication. Therefore, in this study, we described our ten years findings and experience with this group of patients and also present a new technique for valve replacement to reduce or altogether abolish the risk of developing AV block after an operation.

\section{Methods}

This is a retrospective study, in Imam Khomeini Hospital Complex, Tehran University of Medical Sciences. Between December 2003 and November 2013, 243 consecutive IVDAs with isolated tricuspid valve endocarditis who underwent tricuspid valve repair or replacement were enrolled. Demographic data of patients are shown in Table 1 . Concerning the high prevalence of AV block after valve replacement, we changed our surgical technique after January 2007. Patients were divided into two separate groups according to the method of valve replacement before and after January 2007(first and second period 
respectively). In the first period, whenever the septal leaflet and valve loss was inevitable in 10 patients, we performed stitches from prosthetic valve cuff to septal annulus directly. In the second period, in 38 patients we interposed a double layer strip of pericardium along the septal annulus to create a new, flexible and reliable annulus. A strip of the pericardium was sewn to the septal annulus with fine prolen $5 / 0$ or $6 / 0$ stitches. In this way, we performed stitches from prosthetic valve cuff to the strip of pericardium instead of septal annulus directly (Figure 1 and 2). We considered three stages of septal leaflet involvement during the destructive process of endocarditis. Stage I, when the lesion was limited to peripheral and central portions of the leaflet, stage II when most of the septal leaflet was involved just to the annulus and stage III when all of the septal leaflet and annulus was destroyed, making complete debridement inevitable.

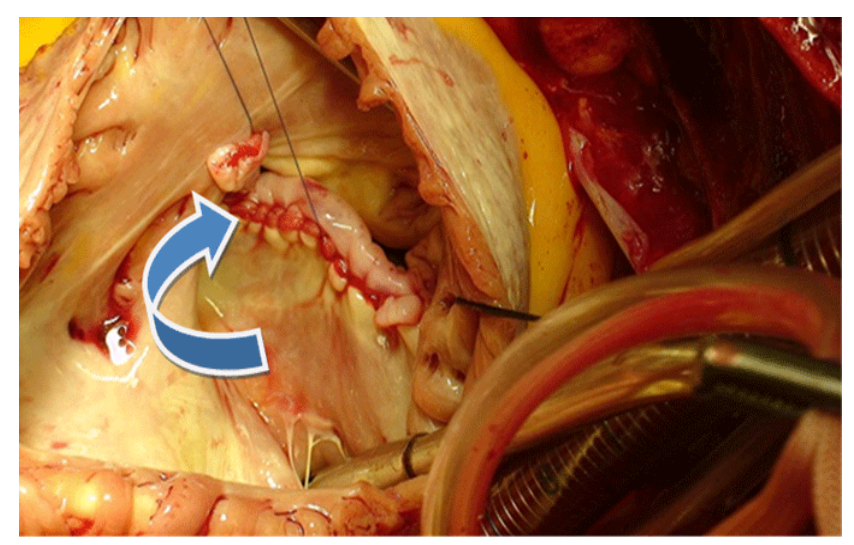

Figure1: Pericardial stripe stitched to septal annulus by $5 / 0$ prolen which work as a new annulus, anchoring valve replacement stitches

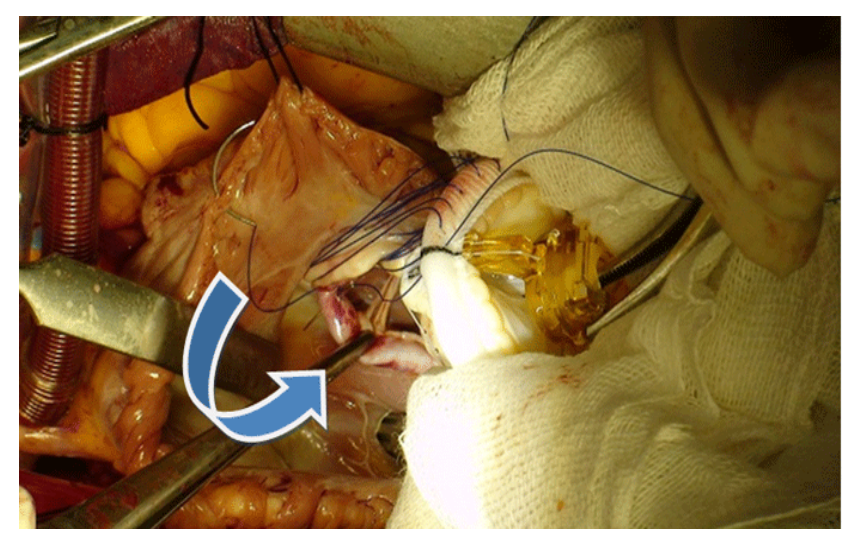

Figure2: Stitches are passing directly from prosthetic valve cuff to pericardial stripe (instead of septal annulus itself) as the new created septal annulus.

The primary strategy in the operating room was valvesparing and repair if feasible. Whenever TVR was inevitable, our favorable valve was a bioprosthetic valve.

Research data were collected retrospectively by trained reviewers using standard data forms. We elicited information including patients' demographics, age, sex, mortality, ICU length of stay, AV block, and kind of procedure (repair or replacement).
Additionally, the type of repair, development of renal failure, need for reoperation, need for a permanent pacemaker after the procedure, continued septicemia after the intervention, and culturing of pathogenic bacteria responsible for endocarditis were also determined.

Follow up was by calling the patients for regular visits. As an encouragement and motivation we paid for expenditures when transfer to Tehran was necessary. Education was provided regarding the increased risk of recurrence and death should poor compliance transpire. When poorly compliant patients were identified, their outcomes were followed by local health care providers.

The study protocol was approved by the institutional MedicoEthical Review committee, and a written informed consent was signed by each patient or his/her relatives before enrollment.

All data were collected retrospectively on standard forms and entered into a computerized database. SPSS version 18 (SPSS, Inc., Chicago IL, USA) was used for statistical analysis. All descriptive data were expressed as a mean \pm standard deviation. A p-value $<0.05$ was considered to be statistically significant. Cumulative survival and freedom from reoperations were analyzed with the Kaplan-Meier actuarial method. A multivariate logistic regression analysis was conducted to predict the impact of the conventional intervention compared to our novel techniques of TVR on developing AV block.

\section{Results}

Mean age of patients was 29 \pm 9.1 years, and 233 (95.8\%) patients were male while $10(4.1 \%)$ patients were female (Table 1). Between December 2003 and January 2007, we performed 60 valve repairs and 10 valve replacements. Between January 2007 and November 2013, we completed 126 valve repairs and 38 valve replacements. Valvectomy (excision of the destroyed leaflets without any repair or replacement) alone was done for 9 patients during the first and second time periods. Different kinds of lesions and techniques for valve repair are shown in Table 2. Tricuspid valve repair in 186 (76.5\%) of the patients comprised the majority of procedures. Valve replacement was unavoidable in $48(19.7 \%)$ of the patients, 10 patients till the end of January 2007 (first period) and 38 patients after that (second period). Our preferred prosthetic valve was a bioprosthetic valve concerning its tolerance and compliance with the lengthy usage of warfarin. ICU length of stay was 2 days in 74 (30.4\%) of the patients, 3 days in 64 (26.3\%) of the patients, 4 days in 95 (39\%) of the patients, more than 7 days in $10(4.1 \%)$ of the patients, and mean ICU stay was $3.2 \pm 1.1$ days. Also, mean hospital stay in cardiac surgery ward was $7.3 \pm 0.8$ days; however because of the need for prolonged intravenous antibiotic therapy after an operation, the average hospital stay was $40.6 \pm 7.6$ days.

Sinus rhythm was seen in 232 (95.4\%) and 224 (92.1\%) patients before and after surgery respectively. Persistent atrial fibrillation was observed in $8(3.2 \%)$ patients after operation, and $\mathrm{AV}$ block was observed in $11(4.5 \%)$ of the patients, in 9 patients till the end of January 2007 and in two patients after 


\begin{tabular}{|c|c|c|}
\hline Item & n: 243 & $\%$ \\
\hline Age (years), mean \pm SD & $29 \pm 9.1$ & \\
\hline \multicolumn{3}{|l|}{ Gender } \\
\hline Male & 233 & $95.8 \%$ \\
\hline Female & 10 & $4.2 \%$ \\
\hline \multicolumn{3}{|l|}{ NYHA class } \\
\hline II & 39 & $16 \%$ \\
\hline III & 193 & $79.4 \%$ \\
\hline IV & 11 & $4.5 \%$ \\
\hline HCV & 109 & $44.8 \%$ \\
\hline HIV & 74 & $30.4 \%$ \\
\hline HBS & 112 & $46 \%$ \\
\hline Euro score II & $22 \pm 17$ & \\
\hline Creatinine (mg/dl) & $2.4 \pm 1.2$ & \\
\hline LVEF \% & $45 \pm 12$ & \\
\hline Total bilirubin $>2 \mathrm{mg} / \mathrm{dl}$ & 53 & $21.8 \%$ \\
\hline Ascites & 12 & $4.9 \%$ \\
\hline \multicolumn{3}{|l|}{ Preoperative Rhythm } \\
\hline Sinus & 232 & $95.4 \%$ \\
\hline Atrial fibrillation & 11 & $4.6 \%$ \\
\hline Septic emboli & 33 & $13.5 \%$ \\
\hline Smoking & 166 & $68.3 \%$ \\
\hline Homeless & 91 & $37.4 \%$ \\
\hline
\end{tabular}

Table 2: Different kinds of lesions and techniques for tricuspid valve repair

\begin{tabular}{|c|c|c|c|c|c|}
\hline Lesion & Technique & $\mathbf{N}$ & $\%$ & 1st & 2nd \\
\hline $\begin{array}{l}\text { Leaflet } \\
\text { perforation }\end{array}$ & $\begin{array}{l}\text { Pericardial patch } \\
\text { repair }\end{array}$ & 24 & 12.9 & 2 & 22 \\
\hline $\begin{array}{l}\text { Leaflet } \\
\text { destruction }\end{array}$ & $\begin{array}{l}\text { Extensive resection } \\
\text { and restoration of } \\
\text { leaflets, } \\
\text { Complete } \\
\text { valvectomy alone }\end{array}$ & 169 & 90.8 & 51 & 118 \\
\hline $\begin{array}{l}\text { Annular } \\
\text { dilatation }\end{array}$ & $\begin{array}{l}\text { Band annuloplasty, } \\
\text { Kay }\end{array}$ & 109 & 58.6 & 32 & 77 \\
\hline $\begin{array}{l}\text { Chordae } \\
\text { rupture }\end{array}$ & $\begin{array}{c}\text { Chordae } \\
\text { transposition or } \\
\text { artificial chordae }\end{array}$ & 63 & 33.8 & 19 & 44 \\
\hline $\begin{array}{l}\text { Papillary } \\
\text { rupture }\end{array}$ & $\begin{array}{l}\text { Resection, Chordae } \\
\text { transposition, flip- } \\
\text { flap }\end{array}$ & 6 & 3.2 & 0 & 6 \\
\hline $\begin{array}{l}1^{\text {st: First time }} \\
2^{\text {nd: }} \text { : econd tin }\end{array}$ & $\begin{array}{l}\text { d of study } \\
\text { riod of study }\end{array}$ & & & & \\
\hline
\end{tabular}

that $(\mathrm{p}=0.00)$. Concerning the impact of two TVR techniques as independent predictors of the development of $\mathrm{AV}$ block as a dependent variable, a test of the full model against a constantonly model was statistically significant, (chi-square $=29.5$, $\mathrm{p}<0.001$ with $\mathrm{df}=1$ ). In our case the Nagelkerke R2 is 0.696 , indicating a moderately strong relationship between predictors and prediction.

Need for a permanent pacemaker (PPM) after operation occurred in $9(18.7 \%)$ of the patients. Reoperation because of reinfection, prosthetic valve endocarditis, progressive valve degeneration, and free tricuspid regurgitation (TR) outcomes led a need in 15 of the patients (Table 5).

Postoperative echocardiography showed no evidence of TR in $109(58.6 \%)$ of the patients, mild to moderate regurgitation in $74(39.7 \%)$ of the patients and severe TR in $3(1.6 \%)$ patients. Moreover, in out of 48 (19.7\%) valve replacement patients, there was paravalvular leakage in 7 of the patients, 6 of them were from the first period.

Staphylococcus aureus was the most common pathogenic bacteria in blood and vegetation culture results in 95 (39\%) of the patients. The incidence of pathogenic organisms and outcome of patients within the first and second period are shown in Tables 3 and 4 respectively. Peripheral septic emboli were detected before operation in $14(5.7 \%)$ patients (Table 6). In 16 (6.5\%) patients, ventilator support was needed for more than 72 hours, and in four of the patients, tracheostomy was necessary because of difficulty in weaning from the ventilator. Persistent septicemia and multiple organ failure were the cause of death after operation in $6(2.4 \%)$ of the patients. We had $30(12.3 \%)$ patients who developed renal dysfunction after the operation. In $22(9 \%)$ patients, hemodialysis was needed and 16 of them died. We had $27(11.1 \%)$ deaths during the hospital stay. However, 30 days mortality was $3.2 \%$. Univariate analysis for in-hospital mortality showed that renal failure was the most significant predictor of mortality ( $p<0.001$, odds ratio: 0.3 and $95 \%$ confidence interval: $0.1-0.8$ ) in our study.

\begin{tabular}{|l|c|c|}
\hline \multicolumn{3}{|c|}{ Table 3: Results of blood and vegetation culture } \\
\hline Organism & Incidence & \% \\
\hline Staphylococcus aureus & 118 & $48.5 \%$ \\
\hline Pseudomonas aeruginosa & 41 & $16.8 \%$ \\
\hline Gram-negative & 42 & $15.9 \%$ \\
\hline Fungus & 4 & $1.5 \%$ \\
\hline Negative culture & 16 & $6.1 \%$ \\
\hline Mix culture & 14 & $5.7 \%$ \\
\hline Miscellaneous & 8 & $3 \%$ \\
\hline
\end{tabular}

Mean survival in our patients was $54.1 \pm 1$ month $(95 \%$ CI: 52.1-56.2). The 30-days, 1 and 5 years survival rate in our patients was $96.7,92.1$ and $88.8 \%$ respectively (Figure 3).

Follow-up time ranged from 1 to 60 months and mean followup time was $52.8 \pm 18.2$ months. Freedom from reoperation at 30 days, 1 and 5 years was 99.5, 98.3 and 93.8\% respectively (Figure 4). 
Table 4: Outcome of patients following all the procedures within the first and second period

\begin{tabular}{|c|c|c|c|c|}
\hline Outcome & Entire patients & 1st period & 2nd period & p-value \\
\hline $\mathbf{A V}^{\pi}$ block after TVR ${ }^{\circledR}$ & $11(22.9 \%)$ & $9(90 \%)$ & $2(5.2 \%)$ & 0.00 \\
\hline Need to PPM ${ }^{\beta}$ & $9(18.7 \%)$ & $7(70 \%)$ & $2(1.1 \%)$ & 0.02 \\
\hline Need to reoperation & $24(9.8 \%)$ & $6(8.5 \%)$ & $18(10.9 \%)$ & 0.66 \\
\hline Overall mortality & $27(11.5 \%)$ & $5(7.1 \%)$ & $22(13.4 \%)$ & 0.09 \\
\hline Mortality after TVR & $18(20.8 \%)$ & $6(60 \%)$ & $6(15.7 \%)$ & 0.04 \\
\hline Mediastinitis & $7(2.8 \%)$ & $2(2.8 \%)$ & $5(2.8 \%)$ & 0.58 \\
\hline Renal failure & $30(12.3 \%)$ & $6(8.5 \%)$ & $24(13.8 \%)$ & 0.85 \\
\hline Cardiac failure & $26(10.6 \%)$ & $7(10 \%)$ & $19(10.9 \%)$ & 0.25 \\
\hline Mesenteric ischemia & $2(0.82 \%)$ & 0 & $2(1.1 \%)$ & 0.45 \\
\hline Tracheostomy & $4(1.64 \%)$ & $1(1.4 \%)$ & $3(1.7 \%)$ & 0.83 \\
\hline
\end{tabular}

T: Atrioventricular

®: Tricuspid valve replacement

$\beta$ : Permanent pacemaker

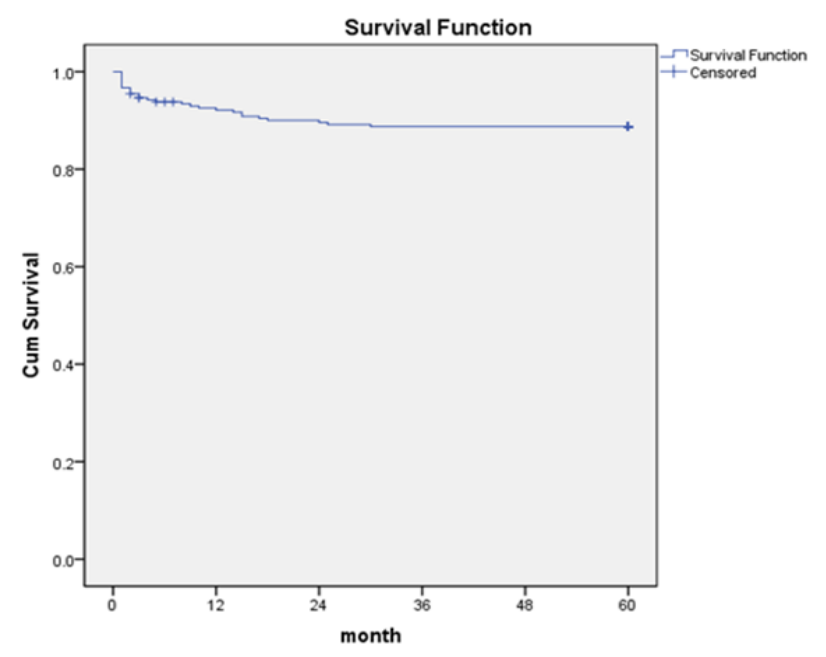

Figure 3: Cum survival (Kaplan-Meier curve)

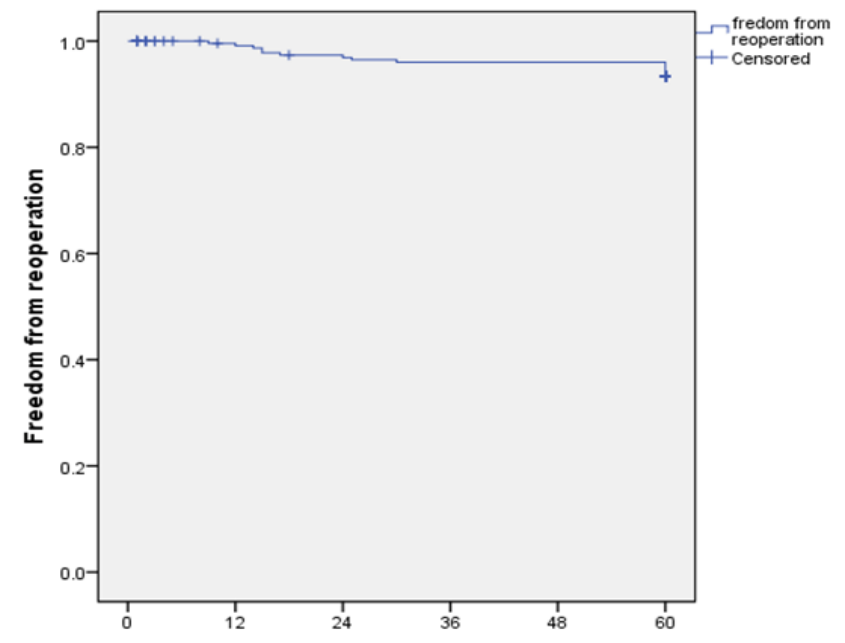

Figure 4: Freedom from reoperation (Kaplan-Meier curve)

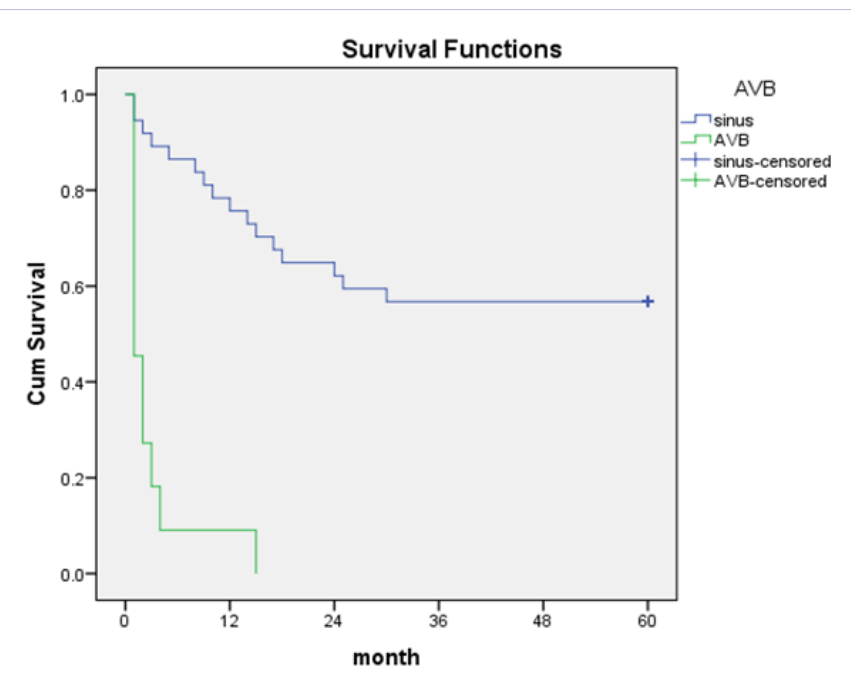

Figure 5: Survival in AV block vs. Sinus rhythm after operation

Mean survival in TVR patients with sinus rhythm after operation was $39.2 \pm 4$ (95\% CI: 31.4-47.1) and in patients with AV block was $2.9 \pm 1.2$ months (95\% CI: 0.46-5.3), (chi-square: 35.1, df: 1, p-value: .000), (Figure 5). Moreover, 1 year survival in different procedures (Mitral valve repair, Mitral valve replacement with bioprosthetic valve and Mitral valve replacement with mechanical valve) illustrated in Figure 6.

Outcomes of patients during follow-up course are shown in Table 4. Causes for reoperation and operative data are presented in Table 5 and 6 retrospectively. 


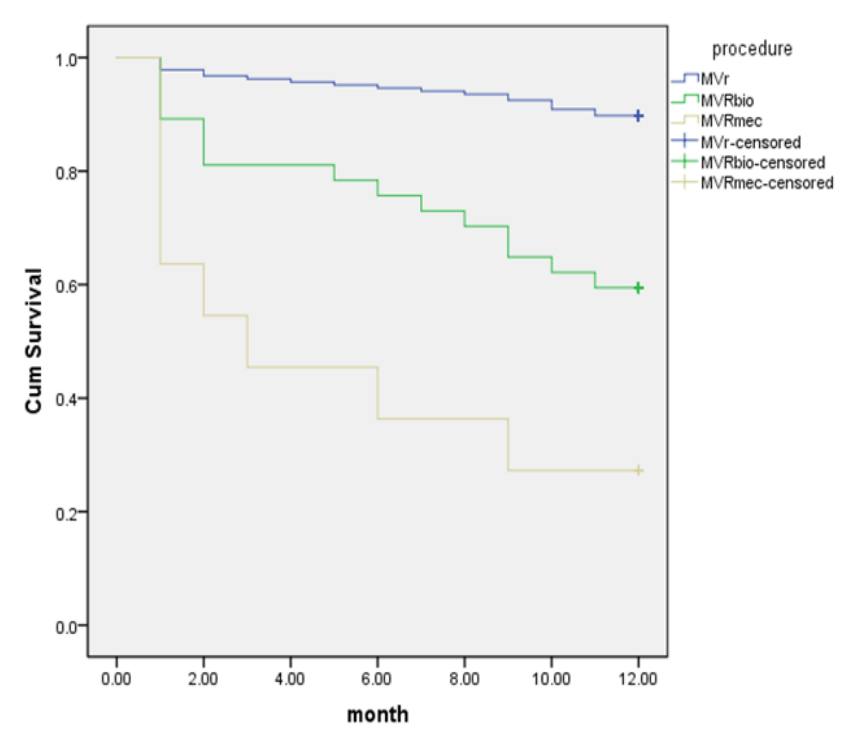

Figure 6: 1 year survival in different procedures (Kaplan-Meier curve) MVr: Mitral valve repair

MVR bio: Mitral valve replacement, bioprosthetic MVR mec: Mitral valve replacement, mechanical

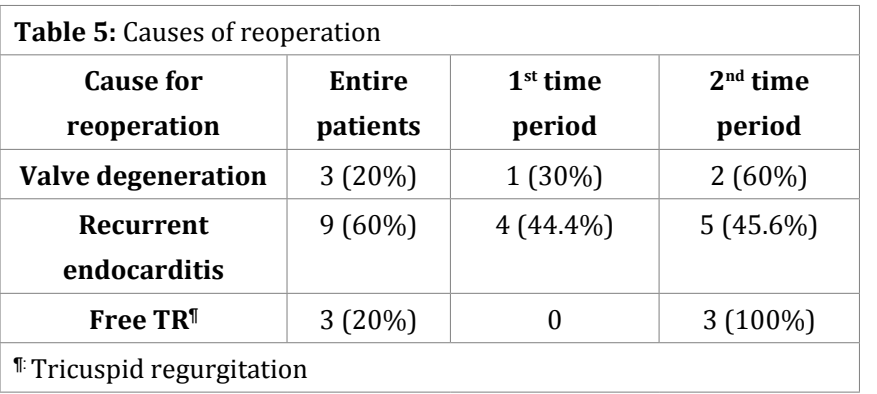

Table 6: Operative data

\begin{tabular}{|c|c|c|}
\hline Item & $\mathbf{n}$ & $\%$ \\
\hline $\begin{array}{l}\text { Urgent } \\
\text { Elective } \\
\text { Emergent }\end{array}$ & $\begin{array}{c}211 \\
19 \\
3\end{array}$ & $\begin{array}{l}90.5 \% \\
8.15 \% \\
1.28 \%\end{array}$ \\
\hline $\begin{array}{l}\text { Beating heart } \\
\text { Arrested heart }\end{array}$ & $\begin{array}{c}56 \\
177\end{array}$ & $\begin{array}{c}23 \% \\
72.8 \%\end{array}$ \\
\hline $\begin{array}{l}\text { Prosthetic valve: } \\
\text { Biological } \\
\text { Mechanical }\end{array}$ & $\begin{array}{c}206 \\
37\end{array}$ & $\begin{array}{l}84.7 \% \\
15.2 \%\end{array}$ \\
\hline Cross-clamp time ( $\mathrm{min}$ ) & $43.7 \pm 5.3$ & \\
\hline $\mathrm{CPB}^{\circledR}$ time ( min ) & $59 \pm 6.3$ & \\
\hline $\begin{array}{l}\text { Simultaneous non-cardiac } \\
\text { surgery: } \\
\text { Splenectomy } \\
\text { Lung lobectomy } \\
\text { Femoral } \\
\text { pseudoaneurysmorhaphy: } \\
\text { Pulmonary embolectomy }\end{array}$ & $\begin{array}{l}5 \\
6 \\
3\end{array}$ & $\begin{array}{c}2 \% \\
2.46 \% \\
1.23 \% \\
1.23 \%\end{array}$ \\
\hline
\end{tabular}

\section{Discussion}

The incidence of TVE is increasing due to growing number of IVDAs and patients having long-term intravenous access for hemodialysis and chemotherapy. TVE has a relatively benign prognosis, and in-hospital mortality is less than $10 \%$. Uncomplicated TVE is successfully treated medically in $80 \%$ of patients; however, in the remaining $20 \%$, surgical treatment is required $[4,5]$.

Our study presents 243 patients with isolated tricuspid valve endocarditis in IVDAs. As many as $90 \%$ of our patients underwent urgent surgery which is defined as surgery within 2448 hours of admission; this was due to our hospital acting as a referral surgical center.

In our cases, $30(12.3 \%)$ of the patients developed renal dysfunction after intervention which is approximately the same as findings by Vigano and Arduino (10 patients, $12.3 \%$ and 2 patients, $13.3 \%$ respectively) but less than that reported by Tarek Mohsen et al (9 patients, 30\%) [6-8]. In another study by Weymann et al, renal failure was developed in 7 (35\%) patients after operation [9].

In 22 patients hemodialysis was required and 16 patients died, suggesting renal failure as the most common cause of death in our patients. In more than one-third of these patients, serum creatinine was more than $2 \mathrm{mg} / \mathrm{dl}$ before the operation. Univariate analysis for in-hospital mortality showed that renal failure was the most significant predictor of mortality $(\mathrm{p}<0.001$, odds ratio: 0.3 and $95 \%$ confidence interval: $0.1-0.8$ ) in our study. Renal complications of IE take at least four forms: prerenal failure secondary to low cardiac output, the formation of microabscess caused by septic emboli, glomerular dysfunction resulting from circulating immune complexes, and renal failure caused by antibiotic toxicity [10].

In our study, AV block was seen in 11 (22.9\%) of the patients after valve replacement, 9 patients in the first period with the conventional technique for valve replacement, and in 2 patients after that $(\mathrm{p}<0.001)$. Of these, permanent pace maker (PPM) was needed in $9(18.7 \%)$ of the patients, 7 patients in the first period and 2 patients in the second period. In the study by Alfieri and co-workers, 28 patients (34.6\%) developed rhythm disorder after TVR, with 7 patients (8.6\%) requiring definitive pacemaker implantation. Also in the study by Arduino A. and his colleagues, need to implant PPM was in $1(6.6 \%)$ of the patients. AV block in our study was significantly lower than that reported by Amr Rouchdy (53.3\% and $13.3 \%$ respectively) [11]. Jokinen et al. reported a rate of $11.1 \% \mathrm{AV}$ block with pacemaker implantation post-tricuspid valve surgery [12].

Although AV block was seen in 11 (22.9\%) of the our patients after valve replacement, it's frequency dropped significantly from $90 \%$ in first time period to $5.2 \%$ in second time period ( $\mathrm{p}$-value= 0.00 ) and therefore comparing the results of other studies with the results of second time period of this study is worthwhile consideration. 
In our study, mean survival in TVR patients with sinus rhythm after operation was $39.2 \pm 4$ (95\% CI: 31.4-47.1) and in patients with AV block was $2.9 \pm 1.2$ months (95\% CI: 0.46-5.3), (chi-square: 35.1, df: 1, p-value: .000), (Figure 5). This statistically significant lower survival in patients with AV block after TVR with the conventional technique in the first time period of this study may be due to a more advanced stage of endocarditis at the time of hospital admission. Advanced stages of endocarditis need more extensive debridement which increases the risk of AV block and other complications after the operation. Leaflet destruction in 169 (69\%) patients was the most frequent lesion in this study. Stage I was seen in 5 patients, stage II in 2 patients and stage III in another 2 patients in the first period. Also, 2 patients in the second period of this study who developed AV block were in stage III who had a need to undergo intervention for extensive debridement of infected and necrotic tissue around the septal annulus. Sinus rhythm was seen in 34 TVR patients in the second period, and therefore we suppose that development of AV block in another 2 patients was not related to our novel technique of valve replacement.

On the impact of two TVR techniques as independent predictors of the development of $\mathrm{AV}$ block as a dependent variable, a test of the full model against a constant-only model was statistically significant, (chi-square $=29.5, \mathrm{p}<.001$ with $\mathrm{df}=$ 1). In our case the Nagelkerke R2 is 0.696 , indicating a moderately strong relationship between predictors and prediction.

Relapsing prosthetic valve endocarditis in 12 of the patients was the most common cause of the need for reoperation in our series. Continuous drug abuse was the cause in a majority of them, although, in 2 patients, recurrent infection was observed after a full course of antibiotic therapy and unrelated to continuous drug abuse. Elective TVR with a bioprosthetic valve was performed for 5 patients months later, while 4 patients died before elective valve replacement.

The choice between biological and mechanical valve is a matter of ongoing debate. The authors of this study, as well as other authorities, agree that biological valve replacement remains a good option in IVDAs respect to limited life expectancy unrelated to the type of tricuspid prostheses at long-term followup [13].

Long-term survival of a patient without a TV is possible, particularly if there is normal pulmonary artery pressure ( PAP ). However, up to $25 \%$ of these patients are not able to tolerate the tricuspid regurgitation. Excision without replacement (valvectomy) can be a viable alternative when other surgical methods are not feasible [14]. In our experience, valvectomy without any other procedure should be performed selectively in patients with low PAP and high risk of reinfection.

In this study, the mortality includes $27(11.5 \%)$ patients, although, 30 days mortality was $4.7 \%$. The 30 -days, 1 and 5 years survival rate in our patients, was 95.3, 90.2 and $87.8 \%$ respectively (Figure 3). Freedom from reoperation at 30 days, 1 and 5 years was 95.3, 93.6 and 90.2\% respectively (Figure 4). In Vigano and Alfieri study, actuarial survival at five years was $68 \%$ and overall mortality was $23.5 \%$ [6]. Also in study by Musci et al, the 30-day, 1-, 5-, 10- and 20-year survival rate after isolated right sided endocarditis operation was $96.2 \%, 88.4 \%, 73.5 \%, 70.4 \%$ and $57.7 \%$, respectively [15]. In another study by Weymann et al, The overall survival of the patient cohort was $90 \%$ at one year, and remained at $85 \%$ from 3 years to the end of follow-up [9].

Our results agree with others that surgical treatment of this unique group of endocarditis could be performed with good early and mid-term results [14-16].

The message of this article may be that a newly created septal annulus by double layer strip of pericardium might be considered as a new technique to reduce or even eliminate the risk of $\mathrm{AV}$ block after TVR in IVDAs. We did not find such a low incidence of $\mathrm{AV}$ block with subsequent need for implantation of PPM as is noted in other studies [4-8].

The authors of this study recommend this technique of TVR be integrated into the practice of every cardiac surgeon whenever they deal with a case of advanced and aggressive tricuspid valve endocarditis.

\section{Limitation of this study}

The main limitation of our study is its retrospective nature and the subsequent treatment bias that is inherent in such research. Regarding the socioeconomic level of our patients and psychosocial aspects of their personality, the follow-up time of close to 60 months was the most difficult part of this study. The number of samples in this study was small, however the group did an excellent effort to follow up on as many patients as possible. While the clinical data presented is relevant, larger studies are necessary to confirm the findings.

\section{Acknowledgment}

We thank Professor Zahed Hosein Khan for his editorial assistance.

\section{Ethical Approval}

This study have been approved by ethics committee of Tehran University of Medical Sciences, Moreover fully informed written consent was taken from patient him/herself or first degree relatives.

\section{References}

1. Morokuma H, Minato N, Kamohara K, Minematsu N. Three Surgical Cases of Isolated Tricuspid Valve Infective Endocarditis. Ann Thorac Cardiovasc Surg. 2010;16(2):134-138.

2. Baddour LM, Wilson WR, Bayer AS, Fowler VG Jr, Bolger AF, Levison $\mathrm{ME}$, et al. Infective endocarditis: diagnosis, antimicrobial therapy, and management of complications: a statement for healthcare professionals from the Committee on Rheumatic Fever, Endocarditis, and Kawasaki Disease, Council on Cardiovascular Disease in the Young, and the Councils on Clinical Cardiology, Stroke, and Cardiovascular Surgery and Anesthesia. American Heart Association: endorsed by the Infectious Diseases Society of America. Circulation. 2005;111(23):e394-434. doi : 10.1161/CIRCULATIONAHA.105.165564 
3. Ruotsalainen E, Sammalkorpi K, Laine J, Huotari K, Sarna S, Valtonen $\mathrm{V}$, et al. Clinical manifestations and outcome in Staphylococcus aureus endocarditis among injection drug users and nonaddicts: a prospective study of 74 patients. BMC Infect Dis. 2006;6:137.doi: 10.1186/14712334-6-137

4. Carrier M, Hébert Y, Pellerin M, Bouchard D, Perrault LP, Cartier R, et al. Tricuspid valve replacement: An analysis of 25 years of experience at a single center. Ann Thorac Surg. 2003;75(1):47-50.

5. Gottardi R, Bialy J, Devyatko E, Tschernich H, Czerny M, Wolner E, et al. Midterm follow-up of tricuspid valve reconstruction due to active infective endocarditis. Ann Thorac Surg. 2007;84(6):1943-1948. doi : 10.1016/j.athoracsur.2007.04.116

6. Viganò G, Guidotti A, Taramasso M, Giacomini A, Alfieri O. Clinical midterm results after tricuspid valve replacement. Interact Cardiovasc Thorac Surg. 2010;10(5):709-713. doi: 10.1510/icvts.2009.224212

7. Arduino A. Mangonia, Thomas G. DiSalvoa, Gus J. Vlahakesb, Carisi A. Polanczyka, Michael A. Outcome following isolated tricuspid valve replacement. Eur J Cardiothorac Surg. 2001;19(1):68-73.

8. Tarek M, Mohamed H, Mohamed H, El-Sayed A. Outcome After Surgical Treatment of Isolated Native Tricuspid Valve Endocarditis: Six Years Single Institution Experience. Journal of the Egyptian Society of Cardio-Thoracic Surgery. 2012; 20(1-2):119-123

9. Weymann A, Borst T, Popov AF, Sabashnikov A, Bowles C, Schmack B, et al. Surgical treatment of infective endocarditis in active intravenous drug users: a justified procedure? J Cardiothorac Surg. 2014;9:58. doi:

\subsection{6/1749-8090-9-58}

10. Kouchoukos NT, Blackstone EH, Hanley FL, Kirklin JK. Infective endocarditis. Cardiac surgery, 4 th ed. Phyladelphia, Elsevier, Saunders. 2013:679

11. Rouchdy A. Isolated Tricuspid Valve Replacement for Severe Infective Endocarditis: Beating Heart versus Arrested Heart. Journal of The Egyptian Society of Cardio-Thoracic Surgery. 2015; 23(1):49-52.

12. Jokinen JJ, Turpeinen AK, Pitkänen O, Hippeläinen MJ, Hartikainen JE. Pacemaker therapy after tricuspid valve operations: implications on mortality, morbidity, and quality of life. Ann Thorac Surg. 2009;87(6):1806-1814. doi: 10.1016/j.athoracsur.2009.03.048

13. Carrier M, Hébert Y, Pellerin M, Bouchard D, Perrault LP, Cartier R, et al. Tricuspid valve replacement: An analysis of 25 years of experience at a single center. Ann Thorac Surg. 2003;75(1):47-50.

14. Chait RD, Midwall J. Tricuspid Valvectomy: Long-Term Survival and Surgical Options. Clin. Cardiol. 2006;29(2), 83-84.

15. Musci M, Siniawski H, Pasic M, Grauhan O, Weng Y, Meyer R, et al. Surgical treatment of right-sided active infective endocarditis with or without involvement of the left heart: 20-year single center experience. Eur J Cardiothorac Surg. 2007;32(1):118-125. doi : 10.1016/j.ejcts.2007.02.034

16. Cabell $\mathrm{CH}$, Abrutyn E. Progress toward a global understanding of infective endocarditis. Lessons from the International Collaboration on Endocarditis. Cardiol Clin. 2003;21(2):147-158. 